This study aimed to determine the character and severity of DSD in a cohort of autistic children and to identify possible prognostic indicators for targeting specialist support.

Methods 13 able children with autism, sequentially receiving a tertiary neuro-ophthalmic diagnosis of DSD, were followed up over 6 years. Records were retrospectively reviewed for neurodevelopmental and neuro-ophthalmic examination results.

Age-inappropriate configural disruption of elements of drawings was identified in the Beery-VMI Test of Visual-Motor Integration (VMI) as evidence of SIM and standard VMI scores (VMIS) were used to measure the severity of SIM. Still-frame analysis of video was used to confirm diagnoses of OA using the criterion of impaired terminal grip size relative to the target grasped. Severity of visual functional impairment was rated on mean individual Cerebral Visual Impairment Inventory scores (MCVIS) using as reference the 90th percentile cut-off MCVIS of 0.74 for the typically developing population.

Correlation between MCVIS and VMIS was determined by linear regression analysis. Method agreement analysis for OA in central vision and motor coordination impairment (MCI), measured by the Beery Motor Coordination assessment, was determined by Cohen's weighted Kappa statistic (K).

Results Significant correlation was found between MCVIS and VMIS: $\mathbf{r}=-0.77$ [95\%CI: -0.93 to -0.83 ], $p=0.002$. Five children required specialist visual impairment (VI) support. The MCVIS for this group (3.05) differed significantly from the MCVIS for the non-support group (1.91) [difference 95\% CI 0.74-1.55], $\mathbf{p}<0.0001$. Agreement for severe MCI ( $\leq 5$ th percentile) with central OA was significant: $\mathrm{K}=1[95 \%$ CI: 0.46 to 1.54$], \mathrm{p}=\mathbf{0 . 0 0 0 2}$.

Conclusions SIM may account for the visual perceptual impairment seen in ASD and OA may underpin motor impairment. MCVIS and VMIS may be useful indicators of the need for specialist VI support.

\section{G419(P) DEVELOPMENTAL DECODING: NOVEL METHODS TO TACKLE THE MENACE OF CHILDHOOD NEURODISABILITY IN NORTHERN INDIA}

R Bharat, S Choudhary, S Niranjan. Paediatrics, Geniuslane Child Development Centre, Lucknow, India

\subsection{6/archdischild-2018-rcpch.408}

Background There is a lack of integrated services for childhood neurodisability in Northern India.

Methods A Child Development Centre was set up by UKtrained Paediatricians to understand existing problems, plan new interventions and compare outcomes. Children with a diagnosis of neurodisability (developmental delay, behaviour issues and learning problems) were eligible. Children with blindness, deafness, severe quadriplegia and progressive neurological disorders were excluded.

This study was conducted in 2 phases (table 1). In phase 1 (November 2014-November 2016) children were treated using existing interventions led by therapists. Problems were identified and an intervention programme based on developmental decoding and home-based environmental modification was developed and piloted in Phase 2 (December 2016 onwards). Problems: phase 1

- Lack of integrated services.
- Delayed diagnosis and lack of individualised support after diagnosis.

- Independent therapists working in isolation.

- Inadequate parental counselling and support. Parents expecting 'magic cure'. High drop out rate.

Changes for phase 2

- Interventions based on Griffith's 3 developmental assessment and modified based on diagnosis and individual profile. An interventional algorithm (software) was developed which provided individualised intervention plans, monitored child's progress and parental compliance.

- All children work towards functional goals. Final (long-term) goals broken into levels(short-term goals).

- Use of multimedia for parental counselling.

- Parental training for home environment modification.

Results

\begin{tabular}{|c|c|c|c|c|c|c|}
\hline \multirow[t]{2}{*}{ Total $(n=468)$} & \multicolumn{3}{|c|}{ Phase $1(n=357)$} & \multicolumn{3}{|c|}{ Phase $2(n=111)$} \\
\hline & $\begin{array}{l}\text { No of } \\
\text { children }\end{array}$ & $\begin{array}{l}\text { Target } \\
\text { progress } \\
\text { achieved }\end{array}$ & $\begin{array}{l}\text { Drop } \\
\text { outs }\end{array}$ & $\begin{array}{l}\text { No of } \\
\text { children }\end{array}$ & $\begin{array}{l}\text { Target } \\
\text { progress } \\
\text { achieved }\end{array}$ & $\begin{array}{l}\text { Drop } \\
\text { outs }\end{array}$ \\
\hline $\begin{array}{l}\text { Autism } \\
\text { Spectrum } \\
\text { Disorder(ASD) }\end{array}$ & 138 & $24(17.4 \%)$ & $\begin{array}{l}114 \\
(82.6 \%)\end{array}$ & 37 & $19(51.4 \%)$ & $\begin{array}{l}18 \\
(48.6 \%)\end{array}$ \\
\hline Cerebral Palsy & 108 & $18(16 \%)$ & $\begin{array}{l}90 \\
(83.3 \%)\end{array}$ & 40 & $26(65 \%)$ & $\begin{array}{l}14 \\
(35 \%)\end{array}$ \\
\hline $\begin{array}{l}\text { Global } \\
\text { development } \\
\text { delay }\end{array}$ & 50 & $12(24 \%)$ & $\begin{array}{l}38 \\
(76 \%)\end{array}$ & 17 & $12(70 \%)$ & $5(29 \%)$ \\
\hline $\begin{array}{l}\text { Intellectual } \\
\text { disability }\end{array}$ & 47 & $9(19 \%)$ & $\begin{array}{l}36 \\
(76 \%)\end{array}$ & 10 & $7(70 \%)$ & $3(30 \%)$ \\
\hline Dyslexia & 14 & $3(21 \%)$ & $\begin{array}{l}11 \\
(78.5 \%)\end{array}$ & 7 & $4(57 \%)$ & $3(43 \%)$ \\
\hline
\end{tabular}

Phase 2

- Marked improvement in target progress and decline in dropout rate was noted.

- Parents felt motivated and empowered.

Conclusion

- Developmental decoding and environmental modification have shown promising results in the management of childhood neuro-disability across a diaspora of diagnosis.

- Information technology was useful in implementation.

\section{G420(P) BEHAVIOURS THAT CHALLENGE: IMPORTANT PROMPTS FOR COMPREHENSIVE PAEDIATRIC ASSESSMENT?}

S George, KA Horridge. Department of Paediatric Disability, City Hospitals Sunderland NHS Foundation Trust, Sunderland, UK

\subsection{6/archdischild-2018-rcpch.409}

Aim To determine the incidence of previously unrecognised chromosomal, neurodevelopmental (e.g. autism spectrum and attention deficit, learning disability) and other conditions in 